\title{
Transmit-Receive Parabolic Reflectarray to Generate Two Beams per Feed for Multi-Spot Satellite Antennas in Ka-Band
}

\author{
Daniel Martinez-de-Rioja, \\ Yolanda Rodriguez-Vaqueiro,
}

\author{
Eduardo Martinez-de-Rioja, \\ Jose A. Encinar, , Antonio Pino,
}

Marcos Arias, and Giovanni Toso,

\begin{abstract}
This contribution describes the design of a multibeam parabolic reflectarray to produce two adjacent beams per feed in orthogonal Circular Polarization (CP) simultaneously at transmit (Tx) and receive ( $R x)$ frequencies in Ka-band. The Variable Rotation Technique (VRT) has been applied to reflectarray cells based on two types of resonant elements, which makes it possible to provide orthogonal beams at $T x$ and $R x$, as well as to implement an in-band optimization procedure to reduce the cross-polarization. A $90-\mathbf{c m}$ parabolic reflectarray has been designed, manufactured and tested to produce multiple adjacent beams in RHCP and LHCP at both 20 and $30 \mathrm{GHz}$. The results are satisfactory and validate the concept of generating two spaced beams in orthogonal $\mathrm{CP}$ by a single feed, changing the polarization of the beam between $T x$ and $R x$. This concept can be suitable for multispot satellites in Ka-band, enabling to halve the number of onboard antennas and feeds.
\end{abstract}

Index Terms-Reflectarray, multibeam antennas, dual band, circular polarization, satellite antennas, Ka-band.

\section{INTRODUCTION}

$\mathrm{H}$ IGH throughput satellites (HTS) in Ka-band split the service area into a cellular coverage made up of a high number of spots [1]. For both transmission (Tx) and reception
$(\mathrm{Rx})$ bands, the beams are generated at two different frequency sub-bands $\left(f_{1}, f_{2}\right)$ and in two orthogonal polarizations $\left(p_{1}, p_{2}\right)$, giving rise to a four-color reuse scheme [2], as shown in Fig. 1. Typically, four reflectors are required onboard the satellite, operating by a Single-Feed-Per-Beam configuration (each reflector produces the beams associated to a single color at $\mathrm{Tx}$ and $\mathrm{Rx}$ ). Several antenna solutions have been proposed to reduce the number of onboard antennas [3][5], but the cost in efficiency, stowage capacity or complexity is too high compared to the current architecture. Reflectarrays have also been proposed due to their independent operation at different frequencies or polarizations [6].



Fig. 1 Multispot coverage in a four-color reuse scheme.

Reflectarrays can easily operate in dual linear polarization (LP) [7], [8]; however, satellite communications in Ka-band operate in dual circular polarization (CP). The design of reflectarrays to operate independently in dual-CP has widely been studied in the last years: different solutions have been proposed based on polarization selective layers or polarizer layers [9]-[11]. Other solutions are focused on the Variable Rotation Technique (VRT), which makes it possible to introduce opposite phase-shifts in orthogonal CP's [12]-[13]. A parabolic reflectarray was proposed in [14], where the 
parabolic surface focuses the reflected field while the VRT is used to deviate in opposite directions the beams in each orthogonal CP. This concept has been validated experimentally in $[15]$ for a flat reflectarray. In [16] a flat reflectarray deviates the beams in orthogonal CP by VRT at the same time that introduces phase corrections to shape the beams without the need for a parabolic surface.

The antennas described in [14]-[16] operate in a single frequency band. In [17], a reflectarray cell has been proposed to operate by VRT at both Tx and Rx frequencies in Ka-band. A flat reflectarray prototype has recently validated the dualband, dual-CP operation in [18] using the cell described in [17]. Moreover, a $0.65-\mathrm{m}$ parabolic reflectarray with the same operating principle has been proposed in [19] and recently validated in [20] to generate two beams per feed in dual $\mathrm{CP}$ at $\mathrm{Tx}$ and $\mathrm{Rx}$ in Ka-band. In [20], a dual-band reflectarray cell with a split hexagonal-loop around a rectangular patch was used to independently adjust the phases at $\mathrm{Tx}$ and $\mathrm{Rx}$ frequencies, respectively. The cell from [20] presents less degrees of freedom to adjust the phases at $\mathrm{Rx}$ than the cell shown in [17], where two orthogonal sets of three parallel dipoles are used instead of the rectangular patch from [20].

A critical limitation of the previous tested reflectarrays to operate by VRT is the reduction of the cross-polar discrimination (XPD) within the operating frequency bands: in [15], [16] the XPD reaches a minimum value around $10 \mathrm{~dB}$. In [20], the results of XPD are only provided at central frequencies, and it is said that both XPD and C/I deteriorates outside the design frequencies, suggesting that a further optimization must be carried out in a future work to overcome these limitations. In this paper, the degrees of freedom provided by the cell presented in [17] are used to implement an optimization technique within the operational bandwidth [18] to improve the XPD, as suggested in [20]. A $0.9 \mathrm{~m}$ parabolic multilayer reflectarray antenna has been designed, manufactured and tested for the first time, with the purpose of generating two spaced beams per feed in dual CP with improved XPD in a 500-MHz bandwidth for Tx and Rx in Kaband. There are two main improvements with respect to the work presented in [20]:

1) The generation of orthogonal beams at $\mathrm{Tx}$ and $\mathrm{Rx}$, which is a usual requirement for multispot coverages in Ka-band that increases the difficulty of the dual-band design by VRT.

2) The implementation of an in-band optimization to reduce the cross-polar radiation and the maximum directivity at $\mathrm{Rx}$ to match the beam shaping at $\mathrm{Tx}$ and $\mathrm{Rx}$, which is possible by the additional degrees of freedom provided by the three parallel dipoles for each polarization in the proposed cell [17].

These improvements are achieved at the cost of manufacturing a dual-layer reflectarray, with a small increase of the complexity in terms of computational burden and manufacturing with respect to a single-layer reflectarray [20].

In addition to the parabolic reflectarray, a reflector has been fabricated using the same manufacturing process. The measured performance of both antennas has been compared.

\section{MISSION SCENARIO}

This contribution proposes the use of a parabolic reflectarray to generate two spaced beams in orthogonal CP per feed simultaneously at $\mathrm{Tx}$ and $\mathrm{Rx}$ frequencies, with application in HTS systems, since a multi-fed offset parabolic reflectarray could generate half the beams of a four-color multispot coverage. A $1.8 \mathrm{~m}$ parabolic reflectarray should be required to fulfil the specifications in gain defined in HTS systems. Due to the large size of the satellite antenna, the parabolic reflectarray prototype has been scaled by a factor of two (a diameter of $0.9 \mathrm{~m}$ ). The main parameters of a complete antenna system, according to the requirements commonly specified in real HTS applications [21], are defined in Table I together with the adapted requirements to the scaled prototype.

TABLE I

ANTENNA SYSTEM REQURREMENTS

\begin{tabular}{ccc}
\hline \hline Parameter & System & Scaled prototype \\
\hline Number of spots & $>100$ & 2 spots/feed \\
Spot lattice & Triangular & Triangular \\
Spot diameter & $0.65^{\circ}$ & $1.3^{\circ}$ \\
Spot separation & $0.56^{\circ}$ & $1.18^{\circ}$ \\
EOC gain & $>43.8 \mathrm{dBi}$ & $>39 \mathrm{dBi}$ \\
Roll-off factor & $<4.3 \mathrm{~dB}$ & $<4.3 \mathrm{~dB}$ \\
Single Entry C/I & $>20 \mathrm{~dB}$ & $>20 \mathrm{~dB}$ \\
Co-polar/cross-polar & $>20 \mathrm{~dB}$ & $>20 \mathrm{~dB}$ \\
Tx frequencies & $19.2 \mathrm{GHz}-20.2 \mathrm{GHz}$ & $19.45 \mathrm{GHz}-19.95 \mathrm{GHz}$ \\
Rx frequencies & $29.0 \mathrm{GHz}-30.0 \mathrm{GHz}$ & $29.25 \mathrm{GHz}-29.75 \mathrm{GHz}$ \\
\hline \hline
\end{tabular}

The Edge Of Coverage (EOC) gain is defined as the gain level where the spot diameter matches the required value $\left(1.3^{\circ}\right.$ for the proposed prototype). Since only one antenna has been designed, it was decided to maintain the central $\mathrm{Tx}$ and $\mathrm{Rx}$ frequencies (19.7 and $29.5 \mathrm{GHz}$ ) for the prototype, with $500-$ $\mathrm{MHz}$ bands. The co-polar over cross-polar ratio is computed as the XPD at Tx and the cross-polar isolation (XPI) at Rx.

\section{ANTENNA DEFINITION}

\section{A. Definition of the Reflectarray Cell}

The reflectarray cell is a two-layer configuration with two outer symmetrical circular arcs to operate at $\mathrm{Tx}$, and two orthogonal stacked sets of three coupled parallel dipoles to operate at Rx, as shown in Fig. 2. The cell has been defined and characterized in [17], including the experimental validation of a home-made electromagnetic code based on the SD-MoM [22], [23], used for the efficient analysis of the cell response under any angle of incidence. Recently, the same cell has been used in a flat reflectarray prototype [18]. The cell is able to provide an opposite phase shift in each $\mathrm{CP}$ at both $\mathrm{Tx}$ and $\mathrm{Rx}$ frequencies by the independent rotation of the arcs and dipoles, and the adjustment of their lengths: $l_{A 1}, l_{A 2}, l_{B 1}$ and $l_{B 2}$ for the dipoles, and the angle $\Omega$ for the arc (see Fig. 2).

Two $0.787 \mathrm{~mm}$ sheets of IsoClad 933 (nominal values: $\varepsilon_{r}=$ $2.33, \tan \delta=0.0016$ ) have been used for both dielectric layers of the cell. IsoClad 933 provides the necessary flexibility to use on double-curved surfaces with high dimensional stability and mechanical strength [24]. Materials previously used in space applications should be considered for a real scenario, 
such as Qz11/EX-1516, based on a prepreg fabric with quartz fibers and low loss resin, with a germanium coating on the reflectarray elements printed on Kapton to avoid electrostatic discharges (ESD) because of the small conductivity of the germanium coating [25]. The arcs and the upper dipoles will be printed on the top side of the upper Isoclad sheet, while the lower dipoles will be printed on the bottom side of the same sheet. Two layers of $38 \mu \mathrm{m} \mathrm{CuClad} 6250$ bolding film $\left(\varepsilon_{r}=\right.$ $2.32, \tan \delta=0.0013$ ) have been used to bond the two Isoclad sheets. The widths of the arcs and dipoles are 0.2 and $0.4 \mathrm{~mm}$, respectively, the inner radius of the arcs is $2.65 \mathrm{~mm}$, and the separation between dipoles is $1.2 \mathrm{~mm}$ from center to center.

The way to obtain the final cell distribution on the parabolic surface consists on computing a grid of reflectarray cells with constant dimensions along both $x$ and $y$-axis $\left(\mathrm{P}_{\mathrm{X}}\right.$ and $\mathrm{P}_{\mathrm{Y}}$, respectively) placed in the aperture plane of the paraboloid (the area enclosed by the rim of the dish). In this case, the initial dimensions have been fixed to $\mathrm{P}_{\mathrm{X}}=6.3 \mathrm{~mm}$ and $\mathrm{P}_{\mathrm{Y}}=$ $6.5 \mathrm{~mm}$, since the incidence angles on the reflectarray will be larger along the $x$-axis than along the $y$-axis. Then, the periodic grid is projected over the parabolic surface, resulting in a grid of reflectarray cells with slightly variable sizes. Due to the low curvature of the antenna, each cell is analyzed by SD-MoM considering a locally flat and periodic structure, but using the real values of period, angle of incidence and field components corresponding to the position of the cell in the antenna, without any interpolation or look-up table.

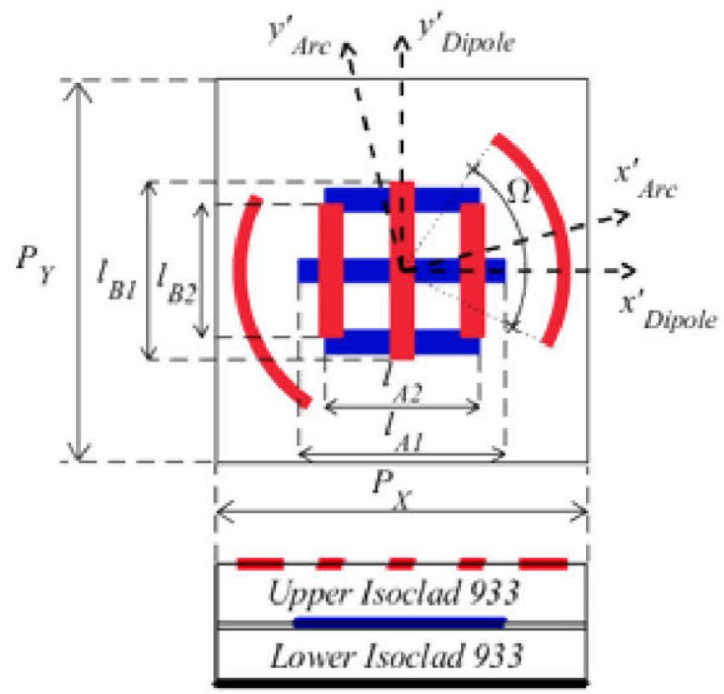

Fig. 2 Top view and lateral view of the reflectarray cell

\section{B. Prototype Configuration}

Based on the antenna configuration that would be required in a real HTS, a prototype has been defined whose dimensions are scaled by a factor of two. The demonstrator consists of a $0.9 \mathrm{~m}$ parabolic reflectarray formed by 15,748 cells. The geometric parameters of the antenna are shown in Table II.

The reflectarray was conceived to be illuminated by a cluster of seven feeds to generate fourteen beams, as shown in Fig. 3 in the normalized angular coordinates $u=\sin \theta \cdot \cos \varphi, v=$ $\sin \theta \cdot \sin \varphi$, where the position of the central horn matches the focus of the paraboloid. However, since the antenna system is symmetric with respect to the $x z$ plane (see Fig. 4) and to simplify the mechanical design, the manufactured prototype considers three different positions of the feed: feed 1,2 and 3 in Fig. 3, generating six beams. A 60-mm diameter dual-band feed-horn developed by Anteral [26] has been used to illuminate the demonstrator. The horn has a directivity of around $21.5 \mathrm{dBi}$ at $19.7 \mathrm{GHz}$ and $23.5 \mathrm{dBi}$ at $29.5 \mathrm{GHz}$, with a minimum XPD of around $25 \mathrm{~dB}$ at both bands. The field radiated by the horn has been modeled using a spherical wave expansion (SWE) distribution. The phase center of the feed at $\mathrm{Rx}$ is shifted with respect to Tx, producing a reduction in gain of around $0.5 \mathrm{~dB}$ at $\mathrm{Rx}$ (this effect is included in the SWE distribution). A half-subtended angle of $18^{\circ}$ has been estimated to get an edge illumination level of $-12 \mathrm{~dB}$ at 19.7 $\mathrm{GHz}$ and $-18 \mathrm{~dB}$ at $29.5 \mathrm{GHz}$. The feed chain also includes a commercial polarizer for terminal stations (ground segment) from General Dynamics [27] with an operational band from 19.4 to $21.20 \mathrm{GHz}$ for $\mathrm{Tx}$, and from 29.2 to $31 \mathrm{GHz}$ for $\mathrm{Rx}$ (model 0183-1416). The polarizer has nominal insertion losses lower than $0.45 \mathrm{~dB}$ at $\mathrm{Tx}$ and $0.35 \mathrm{~dB}$ at $\mathrm{Rx}$, with an axial ratio (AR) lower than $2.3 \mathrm{~dB}$ at $\mathrm{Tx}$ and $1.5 \mathrm{~dB}$ at $\mathrm{Rx}$. The effect of the polarizer is not considered in the simulations. The 3D CAD model of the antenna prototype can be seen in Fig. 4.

TABLE II

\begin{tabular}{cc} 
GEOMETRY OF THE PARABOLIC REFLECTARRAY DEMONSTRATOR \\
\hline \hline Parameter & Requirement \\
\hline Aperture diameter (D) & $906 \mathrm{~mm}$ \\
Focal length (f) & $1359 \mathrm{~mm}$ \\
Offset height ( $\left.\mathrm{h}_{0}\right)$ & $628 \mathrm{~mm}$ \\
Clearance & $175 \mathrm{~mm}$ \\
Half subtended angle & $18^{\circ}$ \\
\hline \hline
\end{tabular}
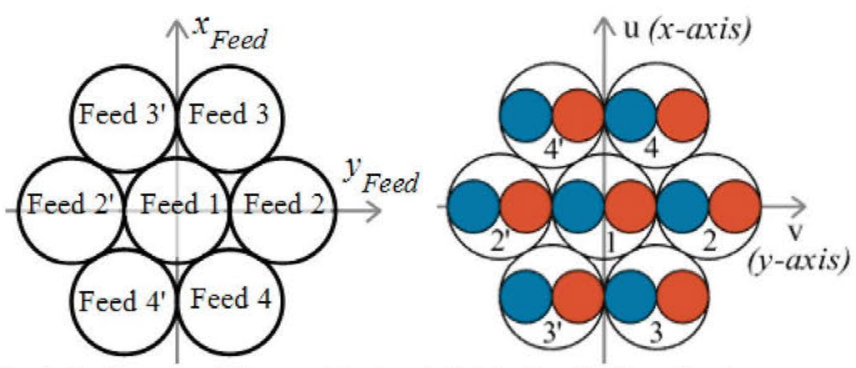

Fig. 3 Feed array and its associated spot distribution for the reflectarray.

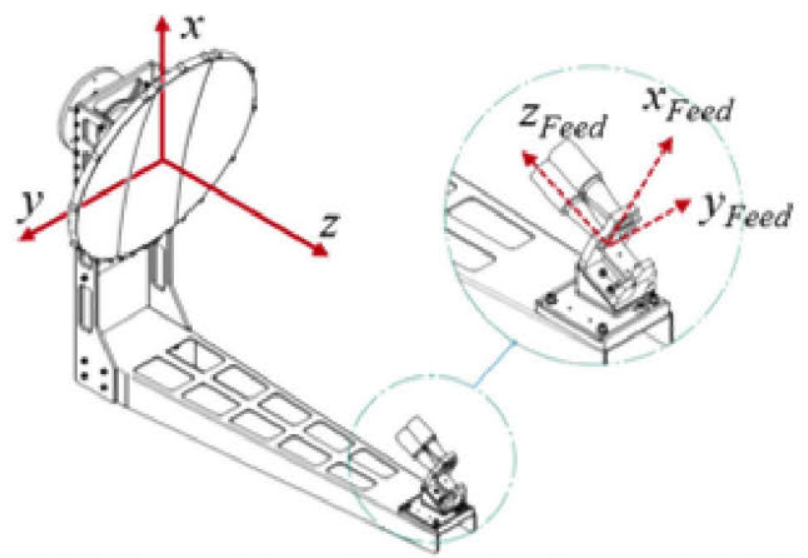

Fig. 4 3D CAD model of the complete antenna breadboard and detailed view of the assembly implemented to change the position of the feed. 


\section{ANTENNA DESIGN AND SIMULATED RESUlTS}

\section{A. Design process of the Antenna}

The rotation angle and dimensions of each group of reflectarray elements are obtained after a step-by-step design process that takes into account the requirements imposed by the VRT and the phase shift distributions required on the reflectarray. The electromagnetic analysis of the reflectarray antenna has been performed by means of a combination of Physical Optics (PO) technique [28] with a realistic model of the reflectarray surface reflection, characterized by SD-MoM considering an infinite periodic surface [22], [23].

The VRT makes it possible to introduce opposite phaseshifts between the orthogonal CP components of the reflected field, where the phase delay introduced in each $\mathrm{CP}$ is proportional to twice the rotation angle of the elements [12]. As proposed in [14], the VRT is used to deviate the beams, while the parabolic surface of the antenna focuses the beams. The rotation angles of the arcs and dipoles are fixed as the phase distributions at $\mathrm{Tx}$ and $\mathrm{Rx}$, respectively, divided by two. Every beam at $\mathrm{Tx}$ is generated in the orthogonal CP than the beam at $\mathrm{Rx}$ (see Fig. 5), following a real requirement of satellite antenna farms. This operation means that the arcs and dipoles rotate in opposite senses, which generates larger differences between the geometry of adjacent cells that increase the difficulty of the antenna design (in [20] the elements rotate in the same sense, generating $\mathrm{Tx}$ and $\mathrm{Rx}$ beams with the same $\mathrm{CP}$ ). The VRT requires to ensure a $180^{\circ}$ phase difference between the two orthogonal linear components of the reflected field to suppress the cross-polar component [12]. Thus, the length of the rotated elements must be adjusted to fulfil this requirement at Tx and $\mathrm{Rx}$ [17].

The aforementioned phase distributions only deviate the beams, producing narrower beams at $\mathrm{Rx}$, due to the larger electrical size of the antenna. As described in [17], the dipoles can be adjusted to control the absolute phase values in the linear components of the field where the $180^{\circ}$ phase difference must be fulfilled, making it possible to introduce phase corrections to slightly reduce the directivity at $\mathrm{Rx}$ to accomplish the roll-off requirement given in Table I. The difference between introducing or not the phase corrections at $29.5 \mathrm{GHz}$ can be seen in Fig. 5, which shows the simulated cuts of the radiation pattern for the designed parabolic reflectarray at $29.5 \mathrm{GHz}$ including both cases, and also the cuts at $19.7 \mathrm{GHz}$. The simulated response at $\mathrm{Tx}$ is barely influenced by the phase correction at $\mathrm{Rx}$, while the $\mathrm{Rx}$ response presents a reduction of $0.6 \mathrm{~dB}$ in the maximum gain as well as a reduction in the side lobe level (SLL). The cuts of the radiation patterns include masks to check the compliance with the requirements. The masks consist of a minimum gain level of $40 \mathrm{dBi}$ with a beamwidth of $1.3^{\circ}$ in the coverage zone of the beam, together with a maximum SLL that is $20 \mathrm{~dB}$ below the previous level and is centered in the coverage area of the adjacent beams (left and right) in the same color.

Previous reflectarrays that operate by VRT [15], [16], [20] present low levels of XPD, mostly attributed to a narrow band performance of the reflectarray cells to provide the $180^{\circ}$ phase difference between the orthogonal linear components of the reflected field. As stated in [18], the arcs at Tx present a more stable behavior in band than the dipoles at Rx. Thus, an optimization has been included to reduce the cross-polar radiation in the $\mathrm{Rx}$ band. The in-band optimization procedure, described in [18], tries to minimize an error function related to the aforementioned phase difference at the extreme and central $\mathrm{Rx}$ frequencies (ideally $180^{\circ}$ ), and it is implemented cell by cell through an adjustment of the dipoles lengths accounting for the real periods, angles of incidence, and field components on each cell, without any interpolation or look-up table.

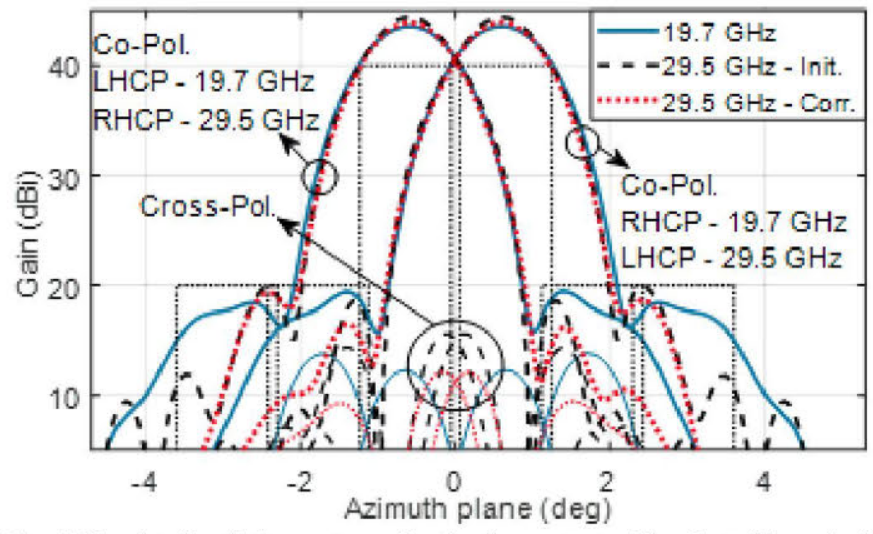

Fig. 5 Simulated radiation patterns for the demonstrator illuminated by a dual$\mathrm{CP}$ feed placed at the focal point of the paraboloid.

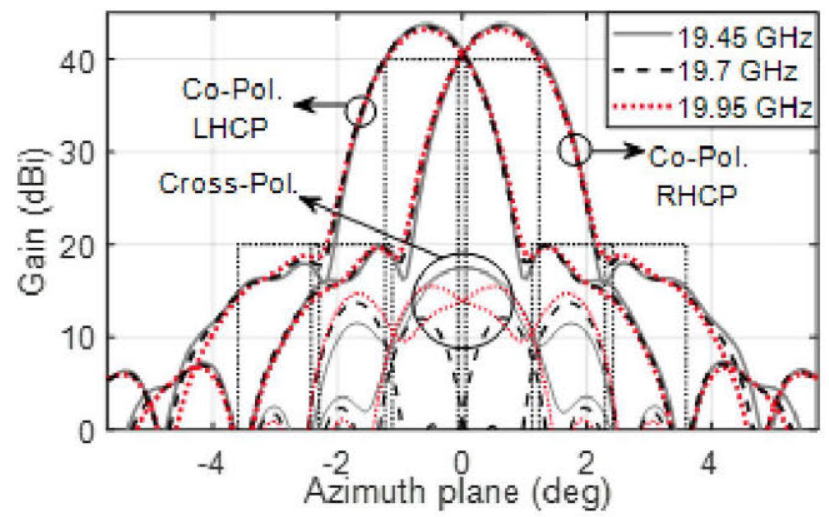

Fig. 6 Simulated radiation patterns for the demonstrator illuminated by a dual$\mathrm{CP}$ feed at the extreme and central frequencies of the Tx band.

The azimuth plane of the simulated radiation patterns at the extreme and central frequencies of each band for the designed parabolic reflectarray is shown in Fig. 6 and Fig. 7 when the reflectarray is illuminated by a dual-CP feed placed at the focal point of the paraboloid. The radiation patterns at $\mathrm{Tx}$ show a XPD larger than $20 \mathrm{~dB}$ that meet the requirements shown in Table I. Fig. 7 includes the radiation patterns at $\mathrm{Rx}$ before (Fig. 7(a)) and after (Fig. 7(b)) implementing the inband optimization. In Fig. 7(a), the minimum of cross-polar radiation is achieved at the design frequency, $29.5 \mathrm{GHz}$ (where the XPI is around $25 \mathrm{~dB}$ ); however, at the extreme frequencies the XPI is reduced to $13 \mathrm{~dB}$. The radiation patterns of the in-band optimized design shown in Fig. 7 (b) achieve an XPI larger than $20 \mathrm{~dB}$ for the complete band. 




(a)



(b)

Fig. 7 Simulated radiation patterns for the demonstrator illuminated by a dual$\mathrm{CP}$ feed at the extreme and central frequencies of the Rx band for (a) a nonoptimized design and (b) an in-band optimized design.

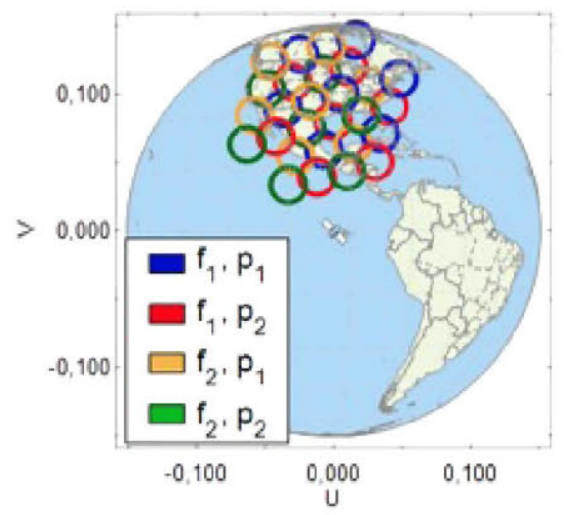

(a)

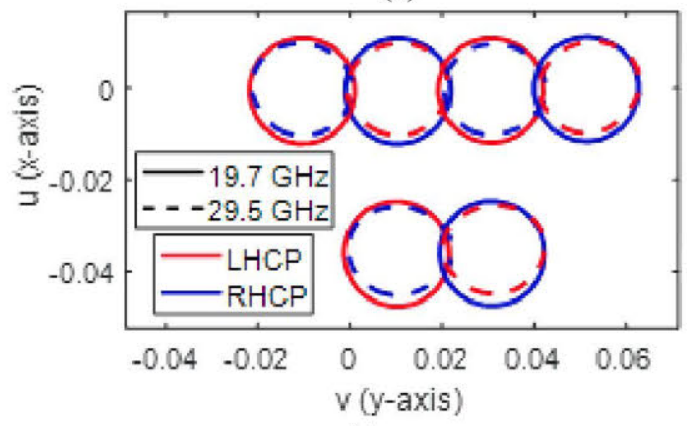

(b)

Fig. 8 (a) 28 spots generated by two $0.9 \mathrm{~m}$ reflectarrays with 7 feeds. (b) Contours of 6 beams generated by one reflectarray at $19.7 \mathrm{GHz}$ and $29.5 \mathrm{GHz}$.

\section{B. Simulated Multibeam Performance}

The radiation patterns of the beams corresponding to the three horns (Feed 1, 2 and 3 in Fig. 3) have been computed at both $\mathrm{Tx}$ and Rx bands. Fig. 8 shows the coverage that would be obtained by two reflectarrays illuminated by the feed array shown in Fig. 3 considering an antenna boresight rotation angle of $75^{\circ}$, together with the simulated pattern contours of the 6 spot-beams at the same gain level $(40 \mathrm{dBi})$ generated by feeds 1,2 and 3 in dual $\mathrm{CP}$ at $19.7 \mathrm{GHz}$ and $29.5 \mathrm{GHz}$. As required, the Tx and $\mathrm{Rx}$ beams are produced in orthogonal $\mathrm{CP}$.

The simulated beams have been evaluated by means of the cuts of the radiation patterns parallel to the principal planes of the triangular spot grid. The cuts in ' $\mathrm{u}=0$ ' are presented in Fig. 9 and Fig. 10 at 19.7 and $29.5 \mathrm{GHz}$. The beams at 19.7 $\mathrm{GHz}$ show a maximum gain of $43.5 \mathrm{dBi}$ with an EOC gain of $40.1 \mathrm{dBi}$. The single-entry $\mathrm{C} / \mathrm{I}$ and XPD are larger than 19.5 $\mathrm{dB}$ and $29 \mathrm{~dB}$, respectively. The simulations at $29.5 \mathrm{GHz}$ present a maximum gain of $43.8 \mathrm{dBi}$, an EOC gain of 39.5 $\mathrm{dBi}$, a minimum single-entry $\mathrm{C} / \mathrm{I}$ and XPI of $18.3 \mathrm{~dB}$ and 25.5 $\mathrm{dB}$, respectively. The minimum values of $\mathrm{C} / \mathrm{I}$ are produced by the beams placed out of the focal point of the paraboloid, which are slightly degraded. The estimated values of the aggregated $\mathrm{C} / \mathrm{I}$ are better than $14 \mathrm{~dB}$ at both $\mathrm{Tx}$ and $\mathrm{Rx}$ bands.

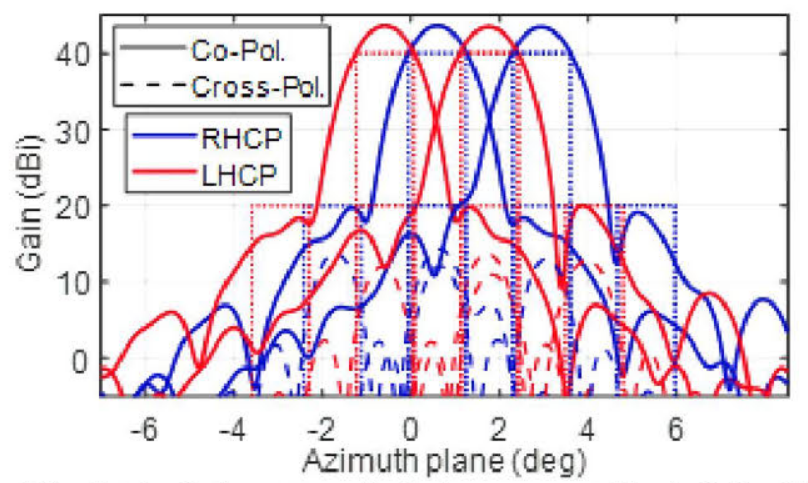

Fig. 9 Simulated radiation patterns for the beams generated by feeds 1 and 2 for the cut ' $\mathrm{u}=0$ ' in LHCP and RHCP at $19.7 \mathrm{GHz}$.

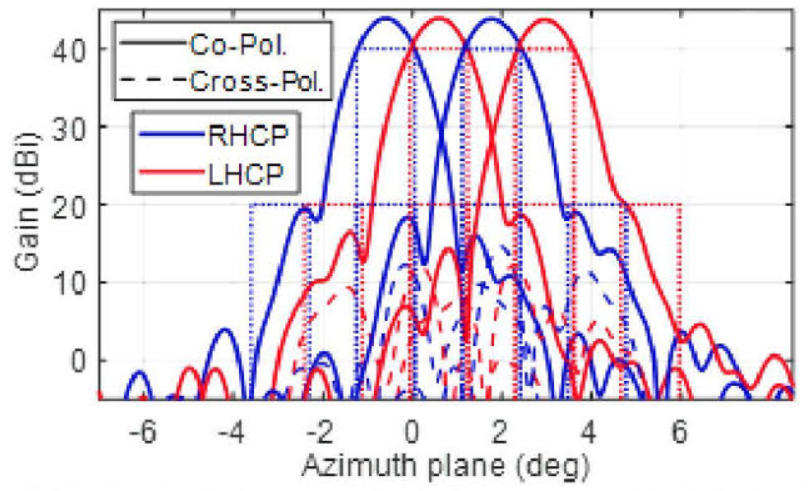

Fig. 10 Simulated radiation patterns for the beams generated by feeds 1 and 2 for the cut ' $\mathrm{u}=0$ ' in LHCP and RHCP at $29.5 \mathrm{GHz}$

The previous simulations have considered only the central frequencies of the Tx and Rx bands. As shown in Fig. 6 and Fig. 7, the limitation in bandwidth imposed by the crosspolarization has been overcome by the implementation of an in-band optimization, which makes it possible to meet the 
cross-polar requirements within $500 \mathrm{MHz}$ bands.

\section{Manufacturing Process of the 0.9 Meter ParaboliC REFLECTARRAY AND A REFERENCE REFLECTOR ANTENNA}

The manufacturing of the copper impressions by photoetching on the IsoClad 933 material was undertaken by the company Trackwise [29]. Due to the large size of the antenna, the upper dielectric layer of the reflectarray, with printed elements on both internal and external sides, was divided in three bands (each around $30-\mathrm{cm}$ wide), as can be seen in the $\mathrm{CAD}$ drawing of Fig. 4 . The second layer, which has not any copper pattern on one side and it is covered by copper on the bottom surface (ground plane), was divided in two bands oriented perpendicular to the three bands of the previous layer.

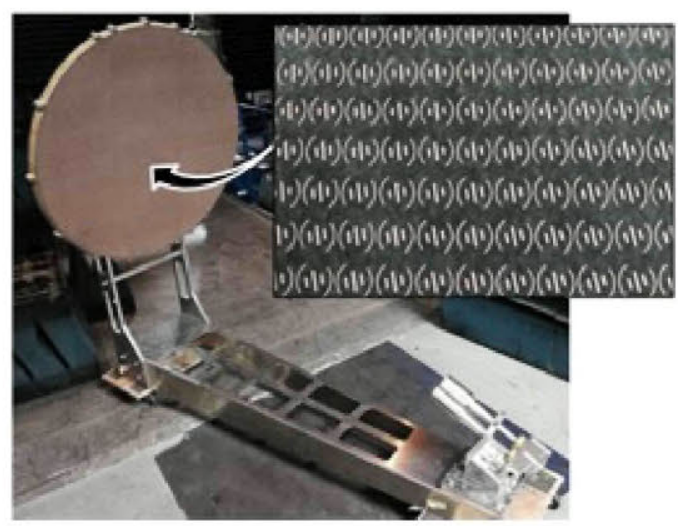

Fig. 11 Manufactured $0.9 \mathrm{~m}$ parabolic reflectarray demonstrator.

Then, the manufacturing process of the antenna system was developed by Acom Sistemas [30]. It includes the manufacture of the Carbon Fiber Reinforced Polymer (CFRP) parabolic sandwich, its integration with the printed arrays on Isoclad 933, and an aluminum support structure to install the feed chain in three different positions (see the CAD model in Fig. 4). First, a low-cost CFRP parabolic mold was manufactured. Then, the three bands with the printed arrays on both sides of the Isoclad 933 were adapted to the mold, as well as the second layer of the Isoclad 933 material cladded with copper on the bottom face, bonded together with the thermoplastic bonding film Cuclad 6250. The final parabolic reflectarray before entering the anechoic chamber of the Universidad Politécnica de Madrid (UPM) can be seen in Fig. 11. A 3D dimensional test of the mold has showed that the Root-MeanSquare (RMS) deviation with respect to the nominal parabolic surface was $0.042 \mathrm{~mm}$. To improve the surface accuracy, an aluminum or Invar mold can be used. In addition, to ensure the necessary thermal stability for space missions, a suitable thermomechanical design of the structural sandwich should be accomplished. Note that the impact of thermo-elastic distortions should be smaller than in conventional "shaped" reflectors despite the presence of dielectrics, because the beam deviation at both bands and the shaping at $\mathrm{Rx}$ is produced by the rotated printed elements and not by the shaping of the reflector surface. The manufacturing process is directly compatible with those used for space CFRP reflectors and dichroic subreflectors used in scientific space missions [31].
Moreover, a reference parabolic reflector with the same configuration than the parabolic reflectarray has also been manufactured and measured in order to compare the performance of the reflectarray with a conventional reflector of identical geometry, and also to identify possible sources of error related to the feed system, antenna alignment, or the antenna structure. The reflector surface has been manufactured by using the same CFRP mold as the reflectarray, changing the dielectric sheets by a copper laminate also divided in three identical bands as the reflectarray prototype.

\section{RF TEST OF THE REFLECTARRAY BREADBOARD}

\section{A. Measurements of the Parabolic Reflectarray}

The manufactured reflectarray and reflector have been measured at the Tx frequencies of 19.2, 19.45, 19.575, 19.7, $19.825,19.95$, and $20.2 \mathrm{GHz}$, and at the $\mathrm{Rx}$ frequencies of 29 , $29.25,29.375,29.5,29.625,29.75,30,30.25$ and $30.5 \mathrm{GHz}$ (the last two frequencies have been tested only for the reflectarray). The measurements have been carried out at the anechoic chamber of the UPM, in a planar near-field measurement system (see Fig. 12), within an angular range of $-0.275<\mathrm{u}<0.275,-0.275<\mathrm{v}<0.275$. The measurements shown in this section represent directivity levels, since the measurement system provides a larger uncertainty in gain $( \pm$ $0.5 \mathrm{~dB})$ than in directivity $( \pm 0.2 \mathrm{~dB})$.

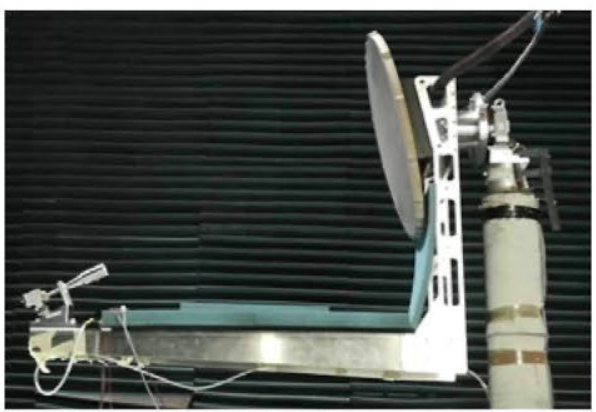

Fig. 12 Manufactured $0.9 \mathrm{~m}$ parabolic reflectarray in the planar near-field measurement system of the UPM.

The measurements of the parabolic reflectarray have been carried out for each position of the feed (central, lateral and upper position) considering both $\mathrm{CP}$ and both frequency bands. Fig. 13 shows the measured multi-spot coverage provided by the parabolic reflectarray at $19.7 \mathrm{GHz}$ and 29.5 $\mathrm{GHz}$. The measured beams generated by the reflectarray at 19.7 $\mathrm{GHz}$ reach values of maximum directivity close to 44 $\mathrm{dBi}$, while the beams generated at $29.5 \mathrm{GHz}$ present a maximum directivity around $45 \mathrm{dBi}$. In contrast, the reflector provides a measured maximum directivity of $44.1 \mathrm{dBi}$ and $45.8 \mathrm{dBi}$ at $19.7 \mathrm{GHz}$ and $29.5 \mathrm{GHz}$, respectively. As expected, the reflectarray at $29.5 \mathrm{GHz}$ provides a smaller directivity than the reflector since the printed dipoles are optimized to reduce the directivity at the $\mathrm{Rx}$ band.

Fig. 14 shows the $40.6 \mathrm{dBi}$-pattern contours of the measured spot-beams generated at 19.7 and $30 \mathrm{GHz}$ by the reflectarray together with the $39.6 \mathrm{dBi}$-pattern contours of the measured beams at $30 \mathrm{GHz}$ generated by the reference 
reflector. Since the reflector cannot discriminate between CP, it generates 3 spot-beams, one per each feed position. The level of the contours has been selected to provide the required spot diameter $\left(1.3^{\circ}\right)$. Note that the reflectarray provides the same EOC gain at both $\mathrm{Tx}$ and $\mathrm{Rx}$ bands, while the reference reflector provides an EOC gain of $39.6 \mathrm{dBi}$ at $30 \mathrm{GHz}$, exceeding the maximum required value of the roll-off factor (the reflector provides the same $\mathrm{EOC}$ gain at $\mathrm{Tx}$ as the reflectarray). Fig. 15 shows the contours of the measured beams produced by the reflectarray at $40.6 \mathrm{dBi}$ (EOC gain), and $20.6 \mathrm{dBi}(20 \mathrm{~dB}$ below the EOC gain), to appreciate the possible interferences between spots in the same color.

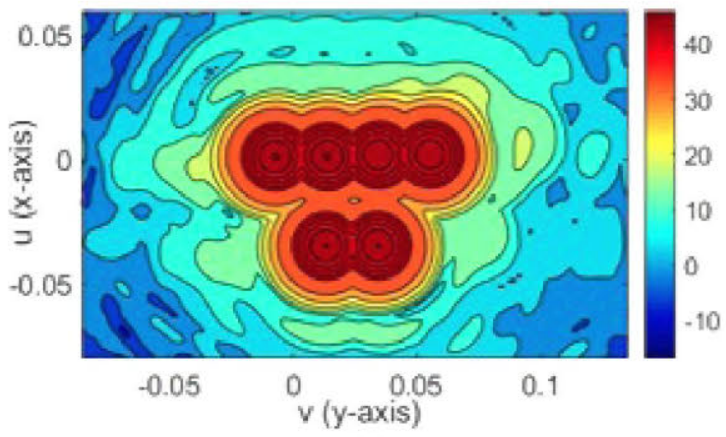

(a)



(b)

Fig. 13 Measured co-polar component of the radiation patterns provided by the reflectarray illuminated by 3 feeds at (a) $19.7 \mathrm{GHz}$ and (b) $29.5 \mathrm{GHz}$.

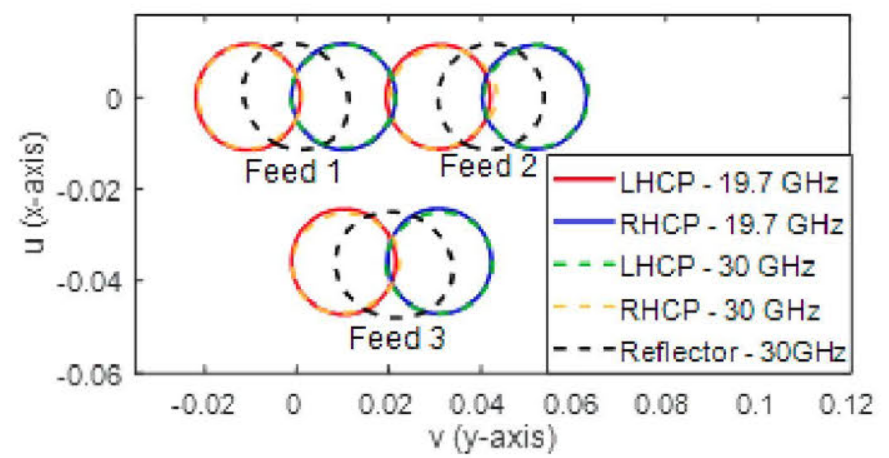

Fig. 14 Measured $40.6 \mathrm{dBi}$ contours of the 6 beams generated by the reflectarray at $19.7 \mathrm{GHz}$ and $30 \mathrm{GHz}$ and measured $39.6 \mathrm{dBi}$ contours of the 3 beams generated by the reflector at $30 \mathrm{GHz}$.

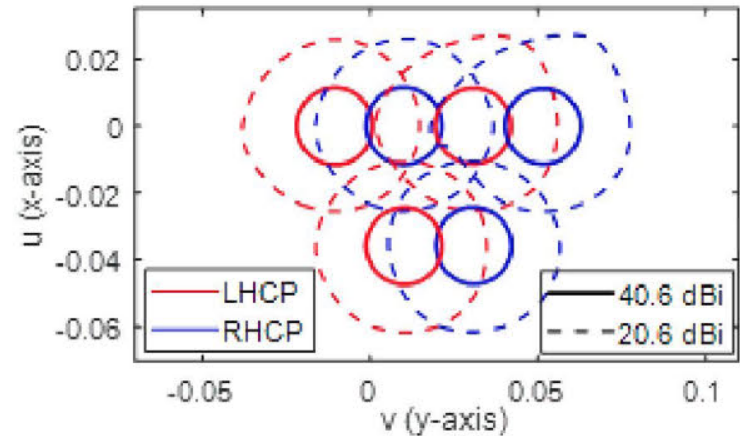

(a)

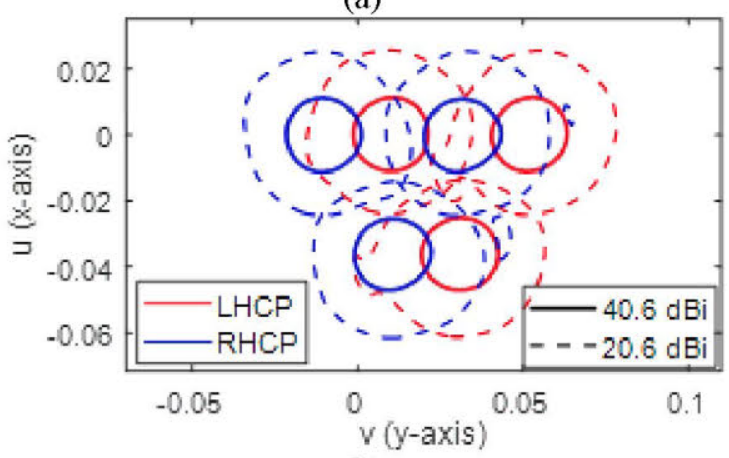

(b)

Fig. 15 Measured contours at $40.6 \mathrm{dBi}$ and $20.6 \mathrm{dBi}$ of the beams generated by the 3 feeds at (a) $19.7 \mathrm{GHz}$ and (b) $30 \mathrm{GHz}$.

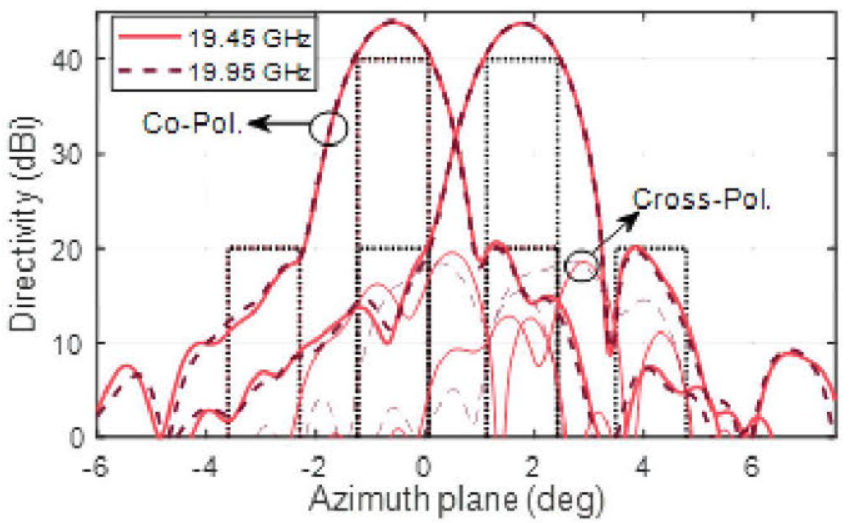

(a)

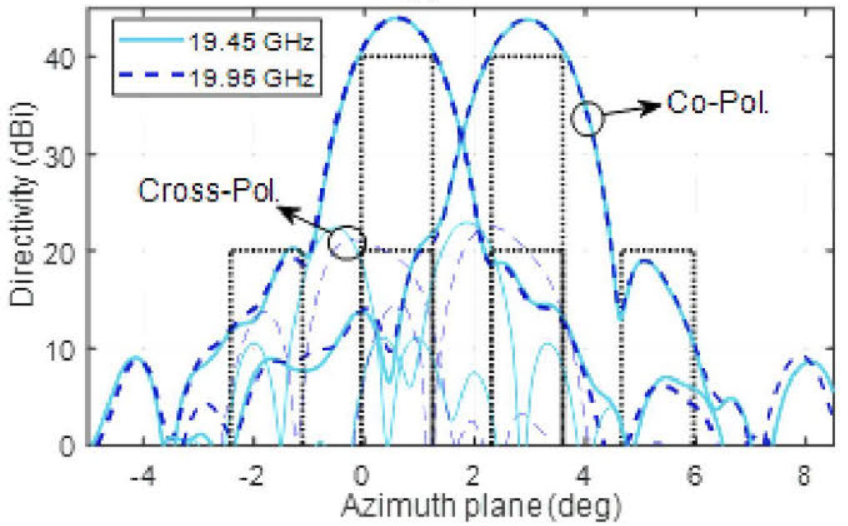

(b)

Fig. 16 Measured radiation patterns for the ' $\mathrm{u}=0$ ' plane at 19.45 and 19.95 $\mathrm{GHz}$ in (a) LHCP and (b) RHCP.

First, the performance of the manufactured reflectarray is 
analyzed at the Tx band. The cuts of the radiation patterns shown in Fig. 16 and Fig. 17 are represented at $19.45 \mathrm{GHz}$ and $19.95 \mathrm{GHz}$, since the higher levels of cross-polar radiation and SLL are reached at the extreme frequencies of the $500 \mathrm{MHz}-$ band. Fig. 16(a) and (b) show the azimuth plane ' $u=0$ ' for the beams generated in LHCP and RHCP, respectively, while Fig. 17 shows the azimuth plane ' $u=-0.036$ '. As can be seen in both figures, the measured beams are close to the specification set by the masks. The six measured beams at $\mathrm{Tx}$ frequencies have a stable maximum directivity close to $44 \mathrm{dBi}$, while the EOC gain remains at $40.6 \mathrm{dBi}$. The single-entry $\mathrm{C} / \mathrm{I}$ is higher than $20 \mathrm{~dB}$ for all beams except for one case, where it reaches a minimum value of $18.8 \mathrm{~dB}$. Finally, the XPD shows values around $20 \mathrm{~dB}$, with a minimum of $17.9 \mathrm{~dB}$. Note that the simulations do not consider the polarizer included in the feed system, which has caused discrepancies in the cross-polar levels (higher in the measurements than in the simulations). The polarizer provides a nominal co-polar over cross-polar ratio of $17.6 \mathrm{~dB}$ in the Tx band, close to the measured XPD of the reflectarray. The inaccuracies in the assembly of the antenna structure and the reflector surface may also increase the measured cross-polar radiation.

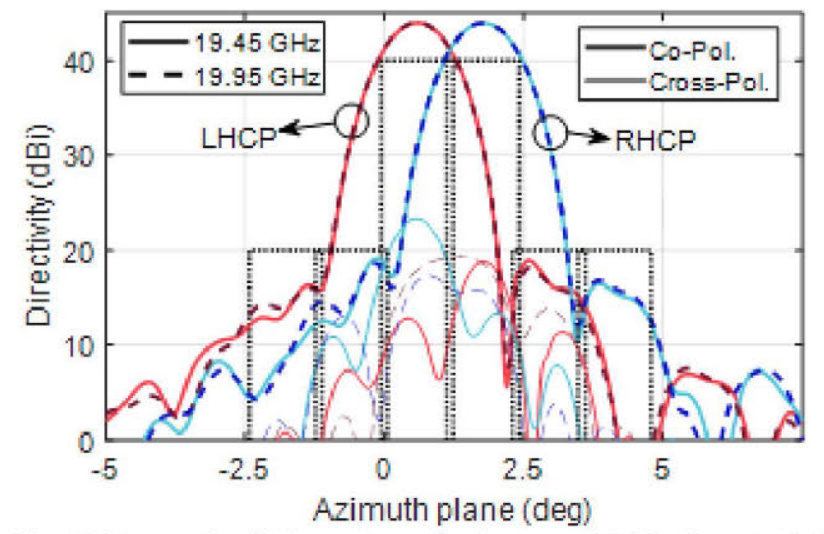

Fig. 17 Measured radiation patterns for the ' $\mathrm{u}=-0.036$ ' plane at 19.45 and $19.95 \mathrm{GHz}$ in LHCP and RHCP.

In order to compare the radiation performance of the reflectarray at the $\mathrm{Tx}$ band with the reference reflector antenna, Fig. 18(a) shows the measured beams at $19.7 \mathrm{GHz}$ produced in dual $\mathrm{CP}$ by both parabolic reflectarray and reflector using the same feed position (feed 1). The measured beams associated to both antennas show similar values of maximum co- and cross-polar levels. Fig. 18(b) also shows the maximum directivity and gain of the measured beams generated by the parabolic reflectarray $\left(\mathrm{D}_{\mathrm{RA}}\right.$ and $\mathrm{G}_{\mathrm{RA}}$ in Fig. 18(b), respectively) together with the maximum directivity and gain produced by reflector antenna ( $\mathrm{D}_{\text {ref }}$ and $\mathrm{G}_{\mathrm{ref}}$ in Fig. 18(b)), both for the case of the antenna illuminated by the central feed in LHCP for the frequencies in which the radiation patterns have been measured in the Tx band.

The difference between the maximum gain and directivity of the reference reflector is caused by the losses introduced by the feed chain, particularly by the polarizer, and by part of the spillover losses (the power radiated outside the measured angular range in the anechoic chamber), which slightly increases the directivity of the measurements. Note that the polarizer introduces larger losses at $19.2 \mathrm{GHz}$, since it is outside its operating band at $\mathrm{Tx}$, and for the rest of frequencies the difference is around $0.6 \mathrm{~dB}$. The difference in directivity between the reflectarray and the reflector, which reaches values lower than $0.2 \mathrm{~dB}$, is produced by the losses associated to the phase errors of the reflectarray elements (not dissipative losses, but energy spread at different directions), proving the excellent performance of the reflectarray to shape the beams at the Tx band (phase errors on the reflectarray surface would produce an increase of the SLL and a reduction in the maximum directivity). Finally, the difference in measured gain between the reflectarray and the reflector comes from the total losses introduced by the reflectarray elements, reaching values lower than $0.4 \mathrm{~dB}$. These losses are caused by the previously defined phase errors $(0.2 \mathrm{~dB})$ and the ohmic losses in the dielectrics $(0.2 \mathrm{~dB})$. The measured losses show an excellent performance of the reflectarray at the $\mathrm{Tx}$ band. The reflectarray gain also shows a small variation of around $0.4 \mathrm{~dB}$ within the 19.45-20.2 GHz band (inside the operating band of the polarizer). There are no differences between the maximum directivity in both $\mathrm{CP}$, although the measured gains for both antennas are $0.4 \mathrm{~dB}$ lower in RHCP than in LHCP, which evidences a deficient performance of the polarizer.

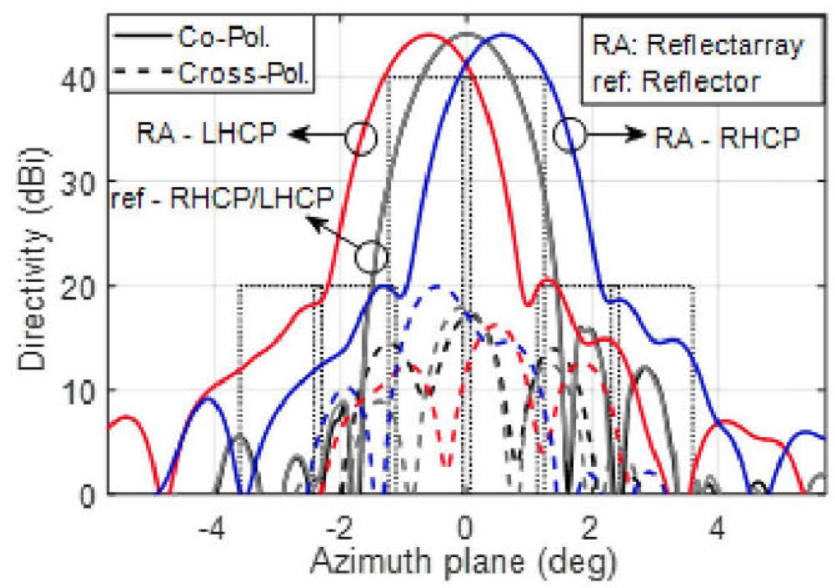

(a)



(b)

Fig. 18 (a) Measured radiation patterns at $19.7 \mathrm{GHz}$ of both parabolic reflectarray and reflector for the same configuration. (b) Maximum measured directivity and gain of both reflectarray and reflector antennas in Tx band. 
Now, the measurements at the $\mathrm{Rx}$ band are shown below (from Fig. 19 to Fig. 22). The measured radiation patterns have revealed a frequency shift in the Rx operating band: the measurements at $30 \mathrm{GHz}$ show a better overall behavior in terms of cross-polar radiation and SLL than at $29.5 \mathrm{GHz}$. Fig. 19 shows the measured beams at $29.5 \mathrm{GHz}$ and $30 \mathrm{GHz}$ produced by the central feed. The frequency shift indicates an imprecise characterization of the dielectrics, which produces phase errors and increases the cross-polar radiation.

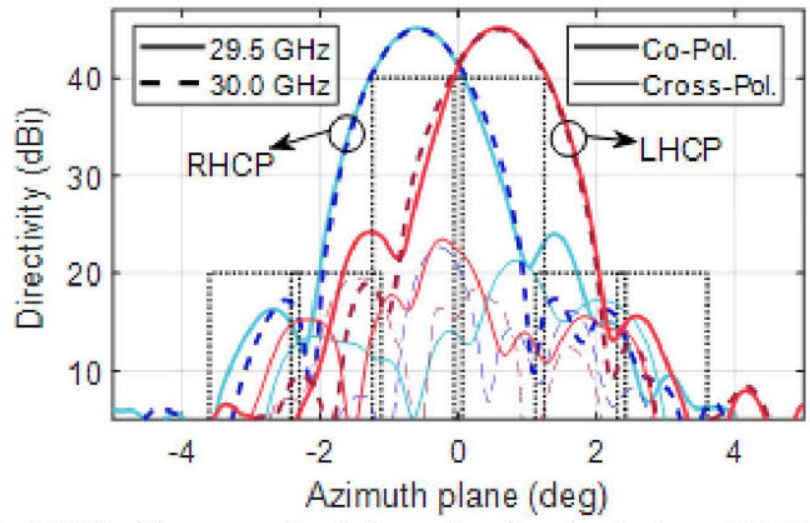

Fig. 19 Cut of the measured radiation pattern for azimuth plane at $29.5 \mathrm{GHz}$ and $30 \mathrm{GHz}$ for the beams generated by feed 1 .



(a)



(b)

Fig. 20 Measured radiation patterns for the ' $u=0$ ' plane at $29.75 \mathrm{GHz}$ and $30.25 \mathrm{GHz}$ in (a) LHCP and (b) RHCP.

According to the measurements, it has been estimated that the central frequency of the band at $\mathrm{Rx}$ is $30 \mathrm{GHz}$, comprising from $29.75 \mathrm{GHz}$ to $30.25 \mathrm{GHz}$. As in the previous analysis at
Tx, the cuts of the radiation patterns shown in Fig. 20 and Fig. 21 present measurements at the extreme frequencies of the band, in order to represent the highest levels of cross-polar radiation and SLL. Fig. 20 and Fig. 21 show the azimuth plane of the measured beams produced by the three feeds (Fig. 20 shows the cut ' $u=0$ ' and Fig. 21 the cut ' $u=-0.036$ '). Both cuts of the radiation patterns present an increase of the SLL at the lower frequency (also noted in Fig. 19), and higher levels of cross-polar radiation in the RHCP measurements.

The six measured beams at $\mathrm{Rx}$ have a maximum directivity close to $45 \mathrm{dBi}, 1 \mathrm{~dB}$ over the maximum directivity at $\mathrm{Tx}$. The EOC gain (computed as the directivity where the spot diameter is $1.3^{\circ}$ ) has remained close to $40.6 \mathrm{dBi}$, the same value that was obtained for the beams in Tx. As a result, the roll-off factor at Rx reaches a level near $4.3 \mathrm{~dB}$. The beams also meet the requirement of single-entry $\mathrm{C} / \mathrm{I}(20 \mathrm{~dB})$ except for one case, where it reaches a minimum value of $18.0 \mathrm{~dB}$. Finally, the XPI does not comply with the required specification; the beams originated from the measurements in LHCP show a XPI that varies from $20.9 \mathrm{~dB}$ to $18.8 \mathrm{~dB}$, while the beams originated from the measurements in RHCP present higher levels of cross-polar radiation, resulting in a XPI between $17.2 \mathrm{~dB}$ and $13 \mathrm{~dB}$, obtained at the upper frequency $(30.25 \mathrm{GHz})$. The differences in the measured cross-polar levels between the beams in RHCP and LHCP are attributed to a deficient performance of the polarizer used in the feed-chain, since the increase in cross-polar radiation caused by phase errors in the VRT implementation affects equally both polarizations. The measurements of the reference reflector also provide a similar minimum XPI of $14 \mathrm{~dB}$, which confirms the unsatisfactory performance of the feed chain.

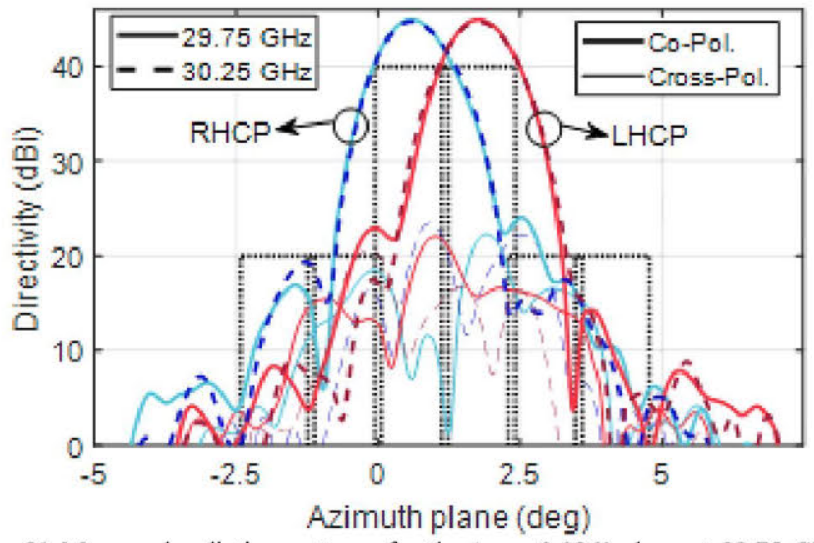

Fig. 21 Measured radiation patterns for the ' $\mathrm{u}=-0.036$ ' plane at $29.75 \mathrm{GHz}$ and $30.25 \mathrm{GHz}$ in LHCP and RHCP.

The comparison between the performance of the parabolic reflectarray and the reference reflector at $\mathrm{Rx}$ is shown in Fig. 22. Fig. 22 (a) shows the measured beams at $30 \mathrm{GHz}$ produced in dual $\mathrm{CP}$ by both antennas using the same feed position (feed 2). In Fig. 22(b), the measured maximum directivity and gain of the reflectarray ( $D_{R A}$ and $\left.G_{R A}\right)$ and the reflector $\left(D_{\text {ref }}\right.$ and $\mathrm{G}_{\mathrm{ref}}$ ) are compared for the case of the antenna illuminated by the lateral feed (feed 2) in LHCP at the Rx band.

The difference between the maximum directivity of the reflectarray and the reflector is larger than the same difference 
at the Tx band because the reflectarray has been designed to introduce a phase correction that reduces the directivity around $0.5 \mathrm{~dB}$ at the $\mathrm{Rx}$ band, in order to match the roll-off requirements. In relation to the gain levels, note that the measurement system provides a relatively large uncertainty in gain $( \pm 0.5 \mathrm{~dB})$, which has caused that two measured gain values for the reflector have soared at 29.25 and $29.375 \mathrm{GHz}$ (marked with red crosses in Fig. 22 (b)). The difference in gain between the reflectarray and the reflector reaches up to $0.7 \mathrm{~dB}$, matching the difference between directivities, which means that the ohmic losses of the dielectric are within the uncertainty in gain of the measured system. As in the Tx frequencies, there are no differences between the measured maximum directivity of the beams in both $\mathrm{CP}$, while the measured gains for both antennas are $0.6 \mathrm{~dB}$ lower for the beams in RHCP than in LHCP, caused by the feed-chain. Note that Fig. 22(a) shows similar cross-polar levels presents for both antennas, slightly higher for the reference reflector, caused by the feed-chain. Therefore, the performance of the parabolic reflectarray at the $\mathrm{Rx}$ band is highly positive.

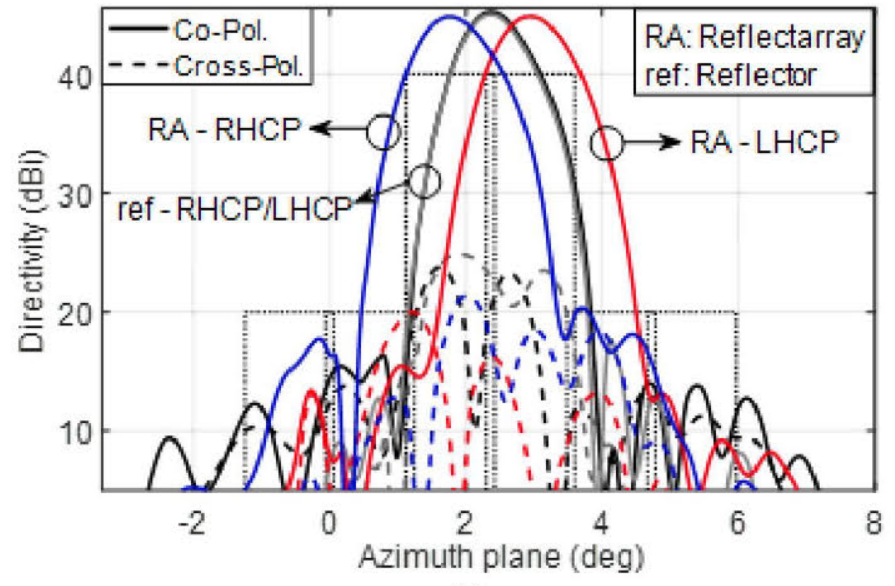

(a)

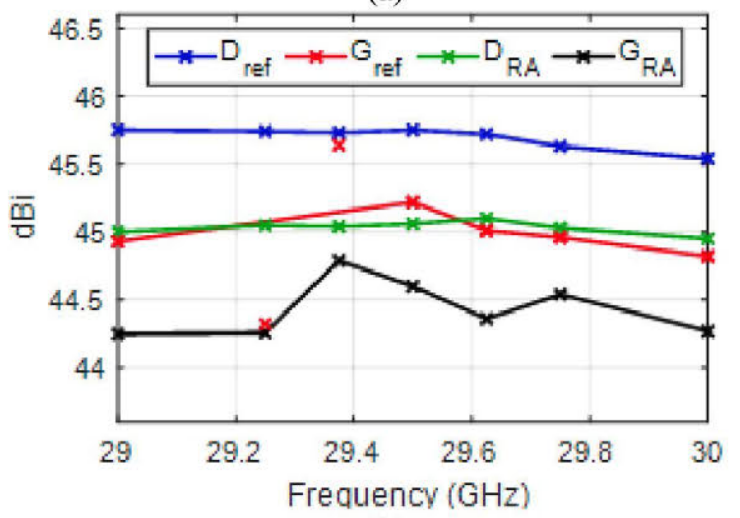

(b)

Fig. 22 (a) Measured radiation patterns at $30 \mathrm{GHz}$ of both parabolic reflectarray and reflector for the same configuration. (b) Maximum measured directivity and gain of both reflectarray and reflector antennas in the Rx band.

A detailed loss budget of the parabolic reflectarray will be shown at the end of the next section, including the information provided by the measurements shown in Fig. 18 and Fig. 22 as well as simulated results to support the measured values. To summarize the measured performance of the parabolic reflectarray, Table III shows the worst measured values within the $500-\mathrm{MHz}$ frequency bands (from 19.45 to $19.95 \mathrm{GHz}$ for $\mathrm{Tx}$, and from 29.75 to $30.25 \mathrm{GHz}$ for $\mathrm{Rx}$ ), considering both polarizations. The same EOC gain level is achieved at Tx and $\mathrm{Rx}$ thanks to the correction of the beam at $\mathrm{Rx}$, the maximum roll-off factor is $0.1 \mathrm{~dB}$ higher than the specification, which falls within the measurement uncertainty, and the minimum single-entry $\mathrm{C} / \mathrm{I}$ is close to the specification, with levels higher than $20 \mathrm{~dB}$ for most of the beams (the frequency shift in $\mathrm{Rx}$ has increased the SLL in that band). Finally, the minimum $\mathrm{XPD}$ at Tx of $17.9 \mathrm{~dB}$ matches the nominal XPD provided by the feed-chain, while the XPI at $\mathrm{Rx}$ shows a minimum value of $18.8 \mathrm{~dB}$ for the LHCP beams and $13 \mathrm{~dB}$ for the beams in RHCP. As aforementioned, the asymmetric performance of the XPI is caused by the polarizer, which also introduces 0.6 $\mathrm{dB}$ of additional losses in the beams in RHCP at $\mathrm{Rx}$ frequencies. The performance in $\mathrm{Rx}$ is also deteriorated due to the frequency shift. However, the measured cross-polar levels are similar to those obtained for the reference reflector, which proves the remarkable behaviour of the reflectarray.

TABLE III

MEASURED IN-BAND PERForMANCE OF THE PARABOLIC REFLECTARRAY

\begin{tabular}{llllll}
\hline \hline Band & $\begin{array}{l}\text { EOC gain } \\
(\mathrm{dBi})\end{array}$ & $\begin{array}{l}\text { Roll-off } \\
(\mathrm{dBi})\end{array}$ & $\begin{array}{l}\text { Single-Entry } \\
\mathrm{C} / \mathrm{I}(\mathrm{dB})\end{array}$ & \multicolumn{2}{c}{ XPD, XPI (dB) } \\
& $\mathrm{RHCP}$ & LHCP \\
\hline $\mathrm{Tx}$ & 40.6 & 3.4 & 18.8 & 18.1 & 17.9 \\
$\mathrm{Rx}$ & 40.6 & 4.4 & 18 & 13 & 18.8 \\
\hline
\end{tabular}

\section{B. Comparison between Measurements and Simulations}

The measurements at Tx show a quite good agreement with the simulated results shown in Section V, with small differences in the maximum levels of the cross-polar radiation, as it was expected, since the cross-polar produced by the feed assembly was not included in the simulations. However, the measurements at Rx present a frequency shift of $0.5 \mathrm{GHz}$ and higher SLL and cross-polar levels than the simulations.

The dimensions of the printed elements were checked after the fabrication, showing an averaged error of $-10 \mu \mathrm{m}$ in the dimensions of both arcs and dipoles, plus a random error of \pm 5 $\mu \mathrm{m}$. This error was included in the simulations, showing a negligible effect at Tx but increasing the SLL at Rx. In order to determine the cause of the shift in frequency at $\mathrm{Rx}$, the electrical properties of the substrate IsoClad 933 has been characterized by some samples formed by two reflectarray cells printed on the same substrate used for the reflectarray. The samples have been measured using the waveguide simulator technique (WGS) to test the performance of the reflectarray cell in a periodic environment [32]. The results showed that the initial permittivity considered in the simulations should be changed to $\varepsilon_{\mathrm{r}}=2.4$.

Note also that the previous simulations showed gain levels, while the measured radiation cuts represent directivity to reduce the uncertainty of the measurement system. To compare both measurements and simulations in directivity, the dissipative losses associated to the substrates have been suppressed in the simulation process. In this way, the 
maximum level of the simulated directivity has increased 0.2 $\mathrm{dB}$ at $19.7 \mathrm{GHz}$ and $0.4 \mathrm{~dB}$ at $29.5 \mathrm{GHz}$. The last effect to be excluded in the simulations is the radiated power outside the angular range of the measurements, increasing the directivity $0.3 \mathrm{~dB}$ at $19.7 \mathrm{GHz}$ and $0.8 \mathrm{~dB}$ at $29.5 \mathrm{GHz}$.

Fig. 23 shows the measured and simulated radiation patterns of the beams generated by the central feed in LHCP at 19.7 $\mathrm{GHz}$ and in RHCP at $29.5 \mathrm{GHz}$, considering the corrected simulations. As can be seen, the measurements and the corrected simulations show an excellent agreement, with a difference between measured and simulated maximum levels of directivity lower than $0.2 \mathrm{~dB}$, which is the uncertainty of the measurements. As aforementioned, the discrepancies in the cross-polar component are caused by the effect of the polarizer in the feed chain, not considered in the simulations.



(a)

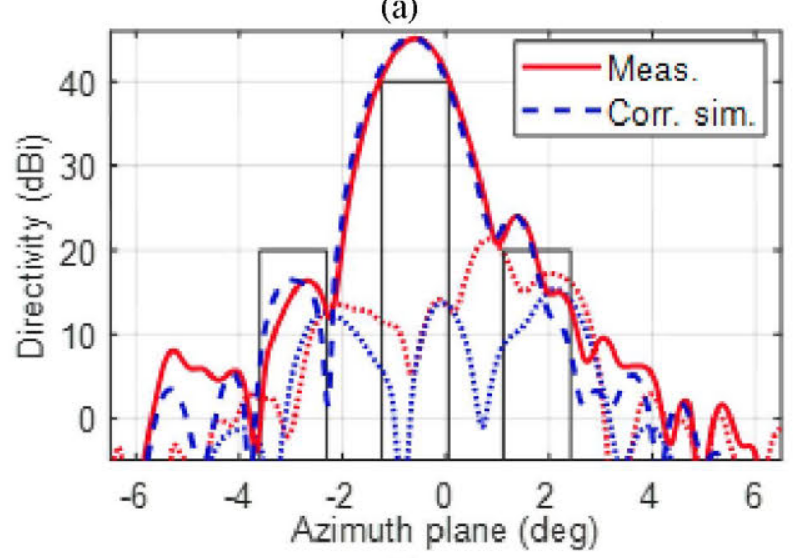

(b)

Fig. 23 Measured and simulated radiation patterns of the beam generated by feed 1 in (a) LHCP at $19.7 \mathrm{GHz}$ and (b) RHCP at $29.5 \mathrm{GHz}$.

A detailed antenna loss budget is shown in Table IV considering the measured directivity and gain of the reference reflector and the parabolic reflectarray ( $\left.D_{\text {ref, }}, G_{\text {ref, }}, D_{R A}, G_{R A}\right)$ shown in Fig. 18 and Fig. 22, and the simulated values provided in this section. The loss budget is divided into three main components. The first component, related to the illumination losses, is the difference between the measured directivity of the reference reflector $\left(\mathrm{D}_{\text {ref }}\right)$ and the theorical directivity of a reflector antenna $\mathrm{D}_{\text {theo }}=10 \log _{10}\left((\pi \cdot \mathrm{D} / \lambda)^{2}\right)$. In contrast to $\mathrm{D}_{\text {theo }}, \mathrm{D}_{\mathrm{ref}}$ includes the losses produced by the taper and spillover efficiencies, and by the shift of the phase center of the feed-horn (only at Rx frequencies) as well as the increment $\xi$ due to the radiated power lost outside the measured angular range in the anechoic chamber. The taper and spillover efficiencies $(67 \%$ and $92 \%$, respectively at $\mathrm{Tx}$, and $48 \%$ and $98 \%$, at $\mathrm{Rx}$ ) have been estimated from the simulated taper illumination in the prototype. The second component, given by the difference between the measured directivity and gain of the reference reflector $\left(D_{\text {ref }}-G_{\text {ref }}\right)$, is composed of the increment $\xi$ and the losses associated to the feed chain. The last component $\left(\mathrm{G}_{\mathrm{ref}}-\mathrm{G}_{\mathrm{RA}}\right)$ represents the losses introduced by the reflectarray elements, which can be divided into the losses associated to phase errors $\left(D_{\text {ref }}-D_{R A}\right)$, and the ohmic losses associated to the substrates. In this way, each component of the table is divided in its main factors, estimated by measurements or simulations, which support each other: the sum of the factors associated to the illumination losses matches the total illumination losses within the uncertainty of the measurements, as well as the resulting feed losses and the nominal insertion losses of the polarizer, or the dielectric losses obtained by measurements and simulations. Table IV proves an excellent performance of the prototype, with a total level of losses introduced by the reflectarray elements similar to that of single-layer reflectarrays [20].

TABLE IV

ANTENNA LosS BUdGET

\begin{tabular}{|c|c|c|c|}
\hline & FIGURE OF MERIT & $\mathrm{Tx}$ & $\mathrm{Rx}$ \\
\hline & Taper illumination & $-12 \mathrm{~dB}$ & $-18 \mathrm{~dB}$ \\
\hline \multirow{5}{*}{$\begin{array}{l}\text { Illumination } \\
\text { losses } \\
\left(D_{\text {theo }}-D_{\text {ref }}\right)\end{array}$} & Total losses & $1.6 \mathrm{~dB}$ & $3.2 \mathrm{~dB}$ \\
\hline & Taper & $1.7 \mathrm{~dB}$ & $3.2 \mathrm{~dB}$ \\
\hline & Spillover & $0.35 \mathrm{~dB}$ & $0.09 \mathrm{~dB}$ \\
\hline & Shift of phase center & $0 \mathrm{~dB}$ & $0.5 \mathrm{~dB}$ \\
\hline & Power lost $(\xi)$ & $-0.3 \mathrm{~dB}$ & $-0.8 \mathrm{~dB}$ \\
\hline \multirow{3}{*}{$\begin{array}{l}\text { Feed losses } \\
\text { and radiated } \\
\text { power lost } \\
\left(D_{\text {ref }}-G_{\text {ref }}\right)\end{array}$} & Total losses & $0.6 \mathrm{~dB}$ & $0.8 \mathrm{~dB}$ \\
\hline & Power lost $(\xi)$ & $0.3 \mathrm{~dB}$ & $0.8 \mathrm{~dB}$ \\
\hline & $\begin{array}{l}\text { Feed losses } \\
\left(D_{\text {ref }}-G_{\text {ref }}\right)-\xi\end{array}$ & $\begin{array}{l}0.3 \mathrm{~dB}(0.45 \\
\mathrm{dB} \text { nominal })\end{array}$ & $\begin{array}{l}0 \mathrm{~dB}(0.35 \mathrm{~dB} \\
\text { nominal })\end{array}$ \\
\hline \multirow{3}{*}{$\begin{array}{l}\text { Reflectarray } \\
\text { losses } \\
\left(\mathrm{G}_{\mathrm{ref}}-\mathrm{G}_{\mathrm{RA}}\right)\end{array}$} & Total losses & $0.4 \mathrm{~dB}$ & $0.7 \mathrm{~dB}$ \\
\hline & $\begin{array}{l}\text { yhase errors } \\
\left(D_{\text {ref }}-D_{R A}\right)\end{array}$ & $0.2 \mathrm{~dB}$ & $0.8 \mathrm{~dB}$ \\
\hline & $\begin{array}{l}\text { Dielectric Losses } \\
\left(\mathrm{G}_{\mathrm{ref}}-\mathrm{G}_{\mathrm{RA}}\right)-\left(\mathrm{D}_{\mathrm{ref}}-\mathrm{D}_{\mathrm{RA}}\right)\end{array}$ & $\begin{array}{l}0.2 \mathrm{~dB}(0.2 \mathrm{~dB} \\
\text { in sims. })\end{array}$ & $\begin{array}{l}0 \mathrm{~dB}(0.4 \mathrm{~dB} \text { in } \\
\text { sims. })\end{array}$ \\
\hline
\end{tabular}

\section{CONCLUSION}

For the first time, a $0.9 \mathrm{~m}$ parabolic multilayer reflectarray has been designed, manufactured and measured to generate two spaced beams per feed in orthogonal CP with improved crosspolarization in the $\mathrm{Tx}$ and $\mathrm{Rx}$ frequencies used in Ka-band satellites. The parabolic reflectarray also demonstrates for the first time that the two beams per feed are in orthogonal $\mathrm{CP}$ at $\mathrm{Tx}$ and $\mathrm{Rx}$ frequencies, while maintaining the cross-polar radiation as moderate as that obtained with an equivalent reflector in the entire frequency bands. The measured results show an excellent behavior with a high degree of compliance with the required specifications. The corrected simulations also show a 
great agreement with the measurements in both frequency bands, validating the design technique, as well as the simulation homemade codes.

This concept can be suitable for multispot satellites in Kaband, since a single parabolic reflectarray can generate half of the required multi-spot coverage (two colors), making it possible to halve the number of antennas and feed-chains required on board the HTS, from four reflectors antennas to two parabolic reflectarray using a SFB configuration.

\section{ACKNOWLEDGMENT}

The authors would like to thank Acom Sistemas for developing the manufacturing process of the antenna system and Trackwise for the photo-etching process of the manufactured reflectarray. The authors would also like to thank Anteral for providing the feed-horn and to Prof. Jorge Teniente from Public University of Navarra, for his valuable help in the feed characterization using spherical mode expansion.

\section{REFERENCES}

[1] H. Fenech, S. Amos, A. Tomatis, and V. Soumpholphakdy, "High throughput satellite systems: An analytical approach," IEEE Trans. Aerosp. Electron. Syst., vol. 51, no. 1, pp. 192-202, Jan. 2015.

[2] M. Schneider, C. Hartwanger and H. Wolf, "Antennas for multiple spot beams satellites", CEAS Space Journal, Vol. 2, pp. 59-66, Dec. 2011.

[3] G. Toso, C. Mangenot and P. Angeletti, "Recent advances on space multibeam antennas based on a single aperture," 7th European Conference on Antennas and Propagation (EuCAP 2013), Gothenburg, 2013, pp. 454-458.

[4] O. M. Bucci, T. Isernia, S. Perna and D. Pinchera, "Isophoric sparse arrays ensuring global coverage in satellite communications", IEEE Trans. Antennas Propag., vol. 62, no. 4, pp. 1607-1618, Apr. 2014.

[5] P. Bosshard et al., "Thales Alenia Space HTS/V-HTS Multiple Beam Antennas Sub-systems on the Right Track", 10th European Conference on Antennas and Propagation (EUCAP 2016), Davos, Switzerland, Apr. 2016, pp.1-5

[6] E. Martinez-de-Rioja, D. Martinez-de-Rioja, J. A. Encinar, A. Pino, B. Gonzalez-Valdes, Y. Rodriguez-Vaqueiro, M. Arias, and G. Toso, "Advanced Multibeam Antenna Configurations Based on Reflectarrays: Providing Multispot Coverage With A Smaller Number of Apertures for Satellite Communications in the $\mathrm{K}$ and $\mathrm{Ka}$ Bands", IEEE Antennas Propag. Mag., Vol. 61, No. 5, pp. 77 - 86, Oct. 2019.

[7] J. A. Encinar, L. Datashvili, J. Agustín Zornoza, M. Arrebola, M. Sierra-Castañer, J. L. Besada, H. Baier, H. Legay "Dual-Polarization Dual-Coverage Reflectarray for Space Applications", IEEE Trans. Antennas Propag., 54(10), 2006, 2827-2837.

[8] S. R. Rengarajan, "Reflectarrays of rectangular microstrip patches for dual-polarization dual-beam radar interferometers", Progress In Electromagnetics Research, Vol. 133, pp. 1-15, 2013.

[9] S. Mener, R. Gillard, R. Sauleau, A. Bellion, and P. Potier, "Dualcircularly polarized reflectarray with independent control of polarizations," IEEE Trans. Antennas Propag., vol. 63, no. 4, pp. 18771881, April 2015.

[10] M. Hosseini and S. V. Hum, "A dual-CP reflectarray unit cell for realizing independently controlled beams for space applications", in Proc. 11th European Conference Antennas Propag. (EuCAP 2017), Paris, France, April 2017, pp. 66-70.

[11] C. S. Geaney, M. Hosseini and S. V. Hum, "Reflectarray Antemnas for Independent Dual Linear and Circular Polarization Control," in IEEE Trans. Antennas Propag., vol. 67, no. 9, pp. 5908-5918, Sept. 2019.

[12] J. Huang and R. J. Pogorzelski, "A Ka-band microstrip reflectarray with elements having variable rotation angles," IEEE Trans. Antennas Propag., vol. 46, no. 5, pp. 650-656, 1998.
[13] T. Smith, U. Gothelf, O. S. Kim, and O. Breinbjerg, "Design, manufacturing, and testing of a $20 / 30-\mathrm{GHz}$ dual-band circularly polarized reflectarray antenna," IEEE Antennas Wireless Propag. Lett., vol. 12, pp. 1480-1483, 2013.

[14] M. Zhou and S. B. Sørensen, "Multi-spot beam reflectarrays for satellite telecommunication applications in Ka-band", Proc. 10th European Conference Antennas Propag. (EuCAP 2016), Davos, 2016, pp.1-5.

[15] A. Somolinos R. Florencio, I. González, J. A. Encinar and F. Cátedra, "Experimental Validation of Generating Two Spaced Beams with Reflectarrays by VRT", IEEE Trans. Antennas Propag., vol. 67, no. 6, pp. $4263-4268$, June 2019.

[16] R. Florencio, J. A. Encinar, R. R. Boix, M. Barba and G. Toso, "Flat Reflectarray that Generates Adjacent Beams by Discriminating in Dual Circular Polarization", IEEE Trans. Antennas Propag., vol. 67, no. 6, pp. 3733 - 3742, June 2019.

[17] D. Martinez-de-Rioja, R. Florencio, J. A. Encinar, E. Carrasco, Rafael R. Boix, "Dual Frequency Reflectarray Cell to Provide Opposite PhaseShift in Dual Circular Polarization with Application in Multibeam Satellite Antennas", IEEE Antennas Wireless Propag. Lett., vol. 18, no. 8, pp. 1591 - 1595, Aug. 2019.

[18] D. Martinez-de-Rioja, R. Florencio, E. Martinez-de-Rioja, M. Arrebola, J. A. Encinar, Rafael R. Boix, "Dual-Band Reflectarray to Generate Two Spaced Beams in Orthogonal Circular Polarization by Variable Rotation Technique", IEEE Trans. Antennas Propag., vol. 68 , no 6, pp. 4617-4626, June 2020.

[19] M. Zhou, S. B. Sørensen, N. Vesterdal, M. F. Palvig, Y. Brand, S. Maltais, J. Bellermore, G. Toso, "Design of Dual-Band Dual-Polarized Reflectarray for Future Multiple Spot Beam Applications in Ka-band", 13th European Conference Antennas Propag. (EuCAP 2019), Krakow, 2019 , pp.1-5.

[20] M. Zhou, S. B. Sørensen, Y. Brand, G. Toso, "Doubly Curved Reflectarray for Dual-Band Multiple Spot Beam Communication Satellites", IEEE Trans. Antennas Propag, vol. 68, no. 3, pp. 2087-2096, March 2020.

[21] H. Fenech, S.Amos, A. Tomatis, V. Soumpholphakdy, "KA-SAT and Future HTS Systems" IEEE 14th International Vacuum Electronics Conference (IVEC 2013), Paris, France, May 2013

[22] R. Florencio, R. R. Boix, E. Carrasco, J.A. Encinar, V. Losada. (2013), "Efficient numerical tool for the analysis and design of reflectarrays based on cells with three parallel dipoles". Microw. Opt. Technol. Lett., Vol. 55, no. 6, pp. 1212-1216, June 2013.

[23] R. Florencio, R. R. Boix and J. A. Encinar, "Efficient Spectral Domain MoM for the Design of Circularly Polarized Reflectarray Antennas Made of Split Rings," in IEEE Trans. Antennas Propag., vol. 67, no. 3, pp. 1760-1771, March 2019.

[24] Rogers IsoClad 933 laminates. [Online]. Available: https://rogerscorp.com/advanced-connectivity-solutions/isoclad-serieslaminates/isoclad-933-laminates, Accessed on April 29, 2020.

[25] J. D. Vacchione, R. C. Kruid, A. Prata, L. R. Amaro and A. P. Mittskus, "Telecommunications antennas for the Juno Mission to Jupiter," 2012 IEEE Aerospace Conference, Big Sky, MT, 2012, pp. 1-16.

[26] Anteral. [Online]. Available: https://anteral.com Accessed on Jan. 04, 2020.

[27] General Dynamics. [Online]. Available: https://www.gd.com/ Accessed on Jan. 29, 2020.

[28] Y. Rahmat-Samii, "A comparison between GO/aperture-field and physical-optics methods of offset reflectors," in IEEE Trans. Antennas Propag., vol. 32, no. 3, pp. 301-306, March 1984. doi: 10.1109/TAP.1984.1143300.

[29] Trackwise. [Online]. Available: https://www.trackwise.co.uk/ Accessed on Jan. 09, 2020.

[30] Acom Sistemas. [Online]. Available: http://acomsistemas.es/ Accessed on Jan. 04, 2020.

[31] R. Caballero, C. Palacios, J. A. Encinar, "Mars Express and Venus Express High Gain Antennas", 27th ESA Antenna workshop on Innovative Periodic Antennas, 9-11 March 2004, Santiago de Compostela, Spain, pp. 83-89.

[32] P. W. Hannan, M. A. Balfour, "Simulation of phased array antennas in waveguides", IEEE Trans. Antennas Propag., Vol. 13, pp. 342-353, May 1965. 